\title{
19. YÜZYIL AZERBAYCAN OKULU VE KURUCULARI
}

\author{
Aybeniz Rahimova ${ }^{1}$ ve Halide Gamze İnce Yakar ${ }^{2}$ \\ ${ }^{1}$ Doç. Dr. Azerbaycan Milli İlimler Akademisi El Yazmalar Enstitüsü, Azerbaycan, \\ aybenizragimova@gmail.com \\ ${ }^{2}$ Yrd. Doç. Dr. Okan Üniversitesi, Türk Dili Bölümü, Türkiye, gamze.yakar@okan.edu.tr
}

\begin{abstract}
Özet
Rusya'nın Azerbaycan'ı işgalinden sonraki dönemde, Azerbaycan'da bin yıllık tarihi olan geleneksel eğitimin sona ermesi ile medreseler kapanmaya ve yeni yöntemler uygulayan okullar faaliyete geçmeye başlamıştı. Azerbaycan'ın toplumsal ve siyasal hayatındaki pek çok değişikliğin yanı sıra eğitimdeki bu yenilikleri halkın kabullenmesi zaman alacaktı. Rus İmparatorluğu'nda memur olarak çalışan M. F. Ahundov, A. Bakıhanov, H. Zerdabi gibi öncülerin çabasıyla Azerbaycan`ın tüm bölgelerinde yeni eğitim sisteminin oluşturulması için mücadele başlatılmıştı. Ülkenin her yerinde imam okulları ve medreselerin yanı sıra Usul-i Cedid (Yeni usul) okulları (uşkollar) da faaliyete geçti. Öncü aydınların çabalarıyla kurulan ve Usul-i Cedid adı verilen okullar hem toplumsal hem de bürokratik açıdan pek çok sorunla karşılaşmıştı. Ancak bu okulların eğitime getirdikleri yenilikler, Azerbaycan'ın geleceği için son derece önemli adımlar sağlayacaktı. Bildirimizde aynı zamanda dönemin önemli edebiyatçıları arasında sayılan Mirze İsmail Gasir ve Seyid Azim Şirvani gibi Usul-i Cedid Okulu kurucularını, yenilikçi fikirleri uygulamaya koyarken yaşadıkları sıkıntıları ve bu okulların eğitime bakış açılarını ele alacağız.
\end{abstract}

Anahtar Kelimeler: Azerbaycan Okulu, Azerbaycan Okulu Kurucuları, Azerbaycan Eğitimi

\section{GiRiş}

Rusya`nın Azerbaycan`ı işgalinden sonra bin yıllık tarihe sahip olan geleneksel eğitim sistemi kötü durumdaydı. Azerbaycan'a Nizamiler, Vagifler, Gövsiler kazandıran eski medrese eğitim sistemi artık görevini tamamlamak üzereydi. Azerbaycan'da, yüzyılın ilk yarısında bilim ve eğitim olduğu gibi devam etse de, artık Avrupa'da ve Rusya'da eğitim modernleşmeye başlamıştı ve bu durum yeni İmparatorlukla tanışmaya başlamış olan aydınları endişelendiriyordu. Rus İmparatorluğu 'nda memur olarak çalışan M. F. Ahundov, A. Bakıhanov, H. Zerdabi gibi öncülerin çabasıyla Azerbaycan`ın tüm bölgelerinde yeni eğitim sisteminin oluşturulması için mücadele başlatılmıştı. Ülkenin her yerinde imam okulları ve medreselerin yanı sıra Usul-i Cedid (Yeni usul) okulları (uşkollar) da faaliyete geçti.

1861 yııında Rus Çarı tahkim hukukunu kaldırdıktan sonra Azerbaycan da dâhil olmak üzere imparatorluk boyunca yeni kapitalist ilişkiler ortaya çıkmaya başladı. Aydınların çabasıyla Gori Semineri nde (okulunda) Azerbaycan (Türk) bölümünün açılması, ülkenin aydınlanması ve yeni eğitim sisteminin bir sonraki zaferi yolunda önemli bir olay haline geldi (Azerbaycan Sovyet Ansiklopedisi, 1979: 287). Halkın yenilikleri kabullenmesi -Bakü de dâhil- oldukça zor oldu. Azerbaycan`ın önemli aydınlarından Elabbas Müznib anılarında şöyle yazıyordu: "Bu dönemlerde Mirze Mecid Ganizade ile Habibi nin 1887 yılında hükümet 
tarafından eğitimlerine devam etmesi için izin verilmiş okul, şekil yönünden Rus eğitimini taklit ettiği için halk arasında pek de sevilmiyordu" (Talışl, 1983).

Şamahı'da S. A. Şirvani, Şuşa'da M. M. Nevvab, İrevan'da M. K. Asgerzade, Nahçıvan`da M. T. Sıtkı yeniliğe açık bölgelerde, Gori Seminari mezunları da şehirlerde "Usul-i Cedid" okulları açsalar da, çok büyük zorluklarla karşılaşıyorlardı. Azerbaycan`ın toplumsal siyasal hayatında, bu dönemde bir sıra yeniliklerin vuku bulduğunu görüyoruz. 1840 yılının Nisan ayında Peterburg, Zakafkasya'da idari reform hakkında kanun verdi. Şemahi şehri, Hazar eyaletinin merkezi olarak ilan edildi. Eyaletin divanhanesi Şemahi'de yerleştiği için devlet hizmetinde bulunan memurların ve aydınların çoğu orada toplanmıştı (Abdullayev,1957: 107).

\subsection{Mirze İsmail Gasir ve Okulu}

İran`ın Eher ve Tebriz şehirlerinde eğitimini bitiren Azerbaycan`ın ünlü şairi ve eğitimcisi Mirze İsmail Gasir, Şirvan`a geri döndükten sonra şehrin yenilikçi aydınlarıyla iletişim kurmuş, edebi yaratıcılığına devam etmişti. Onun bu yeteneğinin farkında olan sonuncu Şirvan Hanı, Mustafa Han`ın oğlu Allahkulu, Mirze İsmail Gasir i kendi oğlu İbrahim `e ders vermeye, onun eğitim ve terbiyesiyle meşgul olmağa davet etti. Geçmiş yıllarda İsfahan da eğitimini tamamladıktan sonra İsfahanlı Seyid Hüseyin Tebetabai' nin oğullarının eğitim, terbiye ve tahsillerinde de belli deneyim toplamış olan Mirze İsmail Gasir bu teklife itiraz etmedi. Seyid Hüseyn 'in evinde öğretmenlik yapması onun "Öğrencilere Kişisel Yaklaşım Yöntemi" ni benimsemesinde olumlu rol oynamıştı. Yolları 19. Yüzyılın önemli bir Azerbaycan aydını olan Sadık Bey Mehmandarov la buluşmuş ve bu buluşma şairin yaşamında büyük bir değişime neden olmuştur. Lenkeran kazasında mahkeme kâtipi görevinde çalışan Sadık Bey Mehmandarov, Mirze İsmail Gasir’i öğretmenlik yapmak için Lenkeran`a davet etmiştir. Mirze İsmail Gasir, Lenkeranda'ki iş faaliyetine mirzelik yapmakla başlamış ve birkaç yıldan sonra eski eğitim sistemine sahip okullardan birinde ders vermeye başlamıştır. Bir müddet sonra kendisi yeni bir "Usul-i Cedid" okulu açmayı hedeflemişti. Sonraki yıllarda Mirze İsmail Gasir, Lenkeran okulunun şekillendirilmesine şahsen katılmış, pedagoji alanında faaliyetlerde bulunmuştur. Bir yandan yoksulluk nedeniyle kendi maddî durumunu iyileştirmek için yollar aramak zorunda bırakmış, öte yandan da buradaki eğitim yöntemlerinin geriliği, onu yeni bir okul oluşturmaya sevk etmiştir (Ahundov,1987: 37-41).

Mirze İsmail Gasir, önce kendi evinde ders vermeyi denemiş fakat eğitim için gerekli alt yapıyı sağlayamaması nedeniyle zorluklar yaşamıştır. Bu durumdan haberdar olan Mirze Sadık Bey Mehmandarov' un teklifini kabul ederek, onun imaretinde oğulları İbrahim Bey, İsak Bey ve Samed Bey’e öğretmenlik yapmağa razı olmuştur. Mirze İsmail Gasir, okul açma isteğini Mehmandarov` un teklifinden birkaç yıl önce gerçekleştirebilmiş fakat maddî zorluklar onun açtığı okulun yardım olmaksızın gelişmesine engel olmuştur. Mirze Sadık Bey’ in yardımıyla Mirze İsmail Gasir in okulu sağlamlaşmış ve Lenkeran ortamında eğitimciliğin yeni ocaklarından birine dönüşmüştür (Memmedov, 1976: 24).

Mirze İsmail Gasir, Okulu'nda, oldukça önemli eğitim yenilikleri uygulanmıştır. Örneğin, okula Kuran getirmeği yasaklamıştır zaten çocuklara verdiği özel eğitim sayesinde onlar kendi başlarına Kuran okuyabiliyorlardı. Dersten teneffüse çıkarken dua verilmesi gibi geleneği iptal etmiş, onun yerine Lenkeran okullarında ilk kez zil çalınması kuralını uygulamıştır. Bu durum, önemli itirazlar oluştursa da zamanla kabul edilmiştir (Talışlı ve Ferzeliyev, 1983).

Mirze İsmail Gasir'in yenilik uğrundaki kavgası, Mehmandarov`un hamiliği sayesinde Gasir Okulu’nun ünlenerek halk tarafından kabul edilmesini sağlamıştır. Ancak ders kitapları ve materyalleri konusunda sıkıntılar yaşanmaktaydı. İmparatorlukta eski alfabe ile kitap basımı zor olduğu için İran'dan getirilen ders malzemelerini kullanmak gerekiyordu fakat bu ders malzemeleri "Usul-i Kadim" medreseleri içindi. Belli ki, "Usul-i Kadim" eğitim sisteminde yalnız Kuran-ı Kerim`in öğretilmesi ve Doğu şairlerinin şiirlerinin ezberletilmesi yeterliydi, Mirze İsmail Gasir ise bunlarla yetinmiyor, eğitim hakkındaki görüşleri kökünden sarsarak, kendi okulunda bir takım yenilikler uygulamaya çalışıyordu (Dadaşov ve Talışlı, 1959).

Mirze İsmail Gasir in Azerbaycan`ın ilk "cedid" ders kitaplarından birini yazması Azerbaycan pedagoji tarihi açısından büyük önem arz etmektedir. 1894 yılında Mirze İsmail Gasir, Farsça gramerine ait "Kanuni-Mirze İsmail Gasir" adlı bir kitap yazmıştır. El yazısı halinde olan bu kitap kısa zamanda ünlenmiş, Mirze İsmail Gasir' in devrinde de, ondan sonra da uzun süre Lenkeran'da ve onun çevresindeki okullarda en çok kullanılan ders kitabı olmuştur. Ders kitabının sunduğu yenilik heceleme yönteminin kaldırılması, harflerin eski isimleriyle değil kelime dâhilinde verdiği sesle gösterilmesidir. Lenkeran okullarının ders kitapları arasında küçük bir "devrim" gibi kabul edilmiş bu ders kitabı şu anda Elyazmaları Enstitüsü'nde muhafaza edilmektedir.

Bu "Usul-i Cedid" okulunun mezunlarının çoğu gelecekte Azerbaycan`ın toplumsal, siyasal ve kültürel hayatında aktif katıımcılar olmuşlardır. Mirze İsmail Gasir in oluşturduğu bu okul, kendi eğitim yöntemine göre Seyid Azim `in Şemahi'de açtığı okula çok benziyordu. Gasir’ in bir eğitimcilik konumu, Azerbaycan`da halk eğitiminin gelişiminde ve pedagoji tarihimizde S. Azim`in tuttuğu konumdan hiç de geri kalmaz. 


\subsection{Seyid Azim Şirvani ve Okulu}

Daha 1830 'lu yıllarda A. Bakıhanov 1832 yılında Baron Rozen`e Bakü de yeni bir okulun tesis edilmesine yönelik bir proje sunmuştur. Bilinmeyen nedenlerden dolayı, onun düzenlediği proje gerçekleşmemiştir (Azerbaycan Tarihi, 1964: 107). Azerbaycan`da ilk kaza okulu 1830 yılında Şuşa`da, 1831 yılında Şeki'de, 1832 yılında Bakü de, 1833 yılında Gence'de, 1837 yılında Şemahi ve Nahçivan'da açılııştır. Bu okullarda Rusça, Azerice, coğrafya ve din dersleri veriliyordu. 1858 yılında Şemahi Guberniyası`nda bir adet dört sınıfı ve dört adet kaza ilkokulu vardı. Bu okullarda 580 öğrenci eğitim görüyordu, Azerbaycan’da ilk kadın okulu 1847 yılında Şemahi' de açılmıştır. 1859 yılında vuku bulmuş korkunç depremden sonra bu okul Bakü'ye nakledilmiştir (Azerbaycan Tarihi, 1964: 107).

Deprem sonucunda büyük hasar görmüş bu şehirde faaliyet gösteren okullar yıkılmış, şehirde yaşam felç olmuştu. İran şahı Nasreddin Şah Gacar Avrupa yı gezdikten sonra Kuzey Azerbaycan, keza Şemahi şehrine de gelmeğe karar verdi (Şirvani, 1968: 228). Şemahi ahalisi, keza S.A.Şirvani Şah`ın gelişini sabırsızıkla bekliyorlardı. Onlar, Şah'ın gelip şehri eski haline döndüreceğini ve okulların onarımını sağlayacağını düşünmüşlerdi. Fakat düşündüklerinin aksi oldu. Şah geldiği gün İran`a geri döndü. Bu ziyaret dönemin aydınları için kendi çarelerini üretmeleri konusunda oldukça çarpıcı bir durum oluşturdu.

Yazılı kaynaklar gösteriyor ki, 1870 yıından itibaren Azerbaycan`ın farklı şehirlerinde olduğu gibi Şemahi'de de mahalle okulları özel şahıslar tarafından organize edilmeye başlanmıştır. Seyid Azim in okuluna ilişkin yazılarda bu okul hakkında geniş bilgilere yer verilmiştir. Bu bakımdan Zaharov makalesinde okulla ilgili aşağıdakileri belirtmiştir:

"Hacı S. A. Şirvani 18 yıl bu okulu yönetmiştir. Kendisi Dağıstan'da eğitim görmüştür. Farsçayı, Arapçayı ve birkaç Dağıstan lehçesini konuşabilmektedir. Rusça okuyup yazabilmekte, Rus edebiyatıyla ilgilenmektedir ve A. Puşkin 'in birkaç şiirini Farsça' ya çevirmiştir. $O$, birinci sınıf şair olarak bilinmektedir. Onun bedii eserlerinden "Ilhan Dakikaları" adlı eseri Tebriz'de yayınlanmış, "Şirvan Hanlığı 'nın Tarihi" adlı bir eser de yazmıştır. Onun okulunda 33 öğrenci eğitim görmektedir, onlardan 12`sinden haftada 15, 9 'undan haftada 20, 12 sinden ise 25 kuruş olmak üzere 6 manat 60 kuruş toplanmaktadır." (Memmedov, 1973: 18).

Seyid Azim, Azerbaycan dili ve din derslerinin eğitimini iyileştirmek amacıyla ders verdiği okullar için ders kitapları da yazmıştır. Seyid Azim Şirvani' nin edebiyat ve pedagoji faaliyetlerinden bahseden araştırmacılar arasında Seyid Azim in ders kitapları konusunda düşünce farklılıkları olmuştur. Bu konuda filoloji bilimleri doktoru, profesör $\mathrm{H}$. Memmedov'un araştırmaları ve vardığı sonuçlar büyük ilgi çekmektedir. Hayrulla Memmedov, Seyid Azim`in yazdığı ders kitaplarının tarihini doğru belirlemiş ve şairin okuldan uzaklaştırımasının nedenlerini inandırıcı şekilde kanıtlamıştır (Memmedov, 1974: 22). Seyid Azim in ders kitaplarının yapısı da H. Memmedov'un düşüncelerini bir daha onaylıyor. Şöyle ki, Seyid Azim her bir ders kitabı için ayrıca "Dibaçe" yazmış ve ders kitabının yazılma amacı ve görevlerini açıklamıştır. "Şariat" ders kitabına gelindiğinde ise, şair onu "yayınlamak amacıyla" 1877 yılının Ekim ayında gönderdiği mektupla Hasanbey Zerdabi' ye başvurmuştur (Memmedov, 1956).

S. A. Şirvani birkaç yıl Şemahi'de açılan okulda ders verdikten sonra tek gelir kaynağı olan öğretmenlik görevinden de onu uzaklaştırmaya çalışanlar olmuştur. 1879 yılının Haziran ayında Bakü Guberniyası ve Dağıstan Eyaleti halk okullarının müdürü Şemahi şehir okulunun gözlemcisine özel telika göndererek, bu yııın 1 Haziran tarihinden Şemahi şehir okulunun öğretmeni Hacı Seyid Azim `i hiçbir neden gösterilmeden görevden alınması ve onun yerine siyasal açıdan daha itibarlı bir öğretmen tayin edilmesi konusunda emir vermiştir. Bununla yetinmeyerek şairin maneviyatını sarsan bir emir vererek, Seyid Azim 'in çocuklara yazdığı varakaları da toplatmıştır (Azerbaycan Sovyet Ansiklopedisi, 1982).

Olayın olduğu gün halk toplanarak, Kafkasya Eğitim Dairesi'nin gözlemcisi K.P.Yanovski'nin adresine dilekçe yazmış ve şehir büyükleri tarafından şikâyet dilekçesi imzalanmıştır. Şair haksız yere okuldan uzaklaştırıldı̆ı kanıtladıktan sonra Bakü Guberniyası Seyid Azim in okula geri kabul edilmesi hakkında karar kabul etmiştir. Seyid Azim in bilinmeyen nedenlerden dolayı görevden alınmasını dikkate alarak tekrar görevine geri dönmesini, Kuran ve belli kitaplar üzere ders vermesini talep etmiştir (Memmedov, 1973: 18). Müfti Hüseyin Efendi, Seyid Azim`in Şemahi şehir devlet okulunda görevine tekrar başlaması için çok çaba sarf etmiş ve sonuçta bunu başarmıştır.

\section{SONUÇ}

Böylece, kişisel yöntemleriyle varlıkı evlerde ve özel okullarda ders vermiş, Azerbaycan`n medreselerinde ve yeni yöntemler uygulayan okullarında öğretmenlik yapmış, büyük başarılar kazanmış, okul açmış, ders kitapları yazma konusunda aktif faaliyet göstermiş Mirze İsmail Gasir ve Seyid Azim Şirvani sadece birer şair veya yeni devir edebiyatımızın teşekkülünde önemli rol oynamış şahsiyetler değil dönemin öncü bir pedagogları olduklarını sergilemeleri de Azerbaycan’ın kültürel eğitim ortamının gelişiminde büyük rol 
oynamıştır. Bu iki önemli pedagog da, Azerbaycan eğitim tarihi bakımından detaylı biçimde incelenmesi gereken çalışmalara imza atmışlardır. Yaşadıkları dönemde hem toplumsal hem bürokratik hem de ekonomik bakımdan zorlu mücadeleler vermiş olan Mirze İsmail Gasir ve Seyid Azim Şirvani, Azerbaycan eğitiminin modern dünyaya açılan iki önemli kapısıdır.

\section{KAYNAKLAR}

Azerbaycan Tarihi. (1964). Bakü. s. 107

Azerbaycan Sovyet Ansiklopedisi. (1979). cilt 3. Bakü. s. 287

Ahundov, i. (1981). Hatıralarımda Yaşayan Lenkaran. Bakü. s. 37-41

Memmedov, A. (1976). Mirze İsmail Gasir ve Onun Elyazmaları. Elyazmalar Hazinesi cilt 4. Bakü. s.24

Rahimova, A. (2002). Mirze İsmail Gasir. Bakü. s. 47

Talışı M. ve Ferzeliyev V. (1983). Mirze İsmail Gasir. Azerbaycan Muallimi. 8Temmuz 1983

Dadaşov M. ve Talışlı M. (1959). Fövcül- Füsaha Edebi Meclis Hakkında. Leninci Gazetesi, 20 Eylül 1959

Şirvani, S. A. (1969). Eserleri. Cilt 11, Bakü. s. 228

Memmedov, H. (1973). Seyid Azim Hakkında Hakikat. ADPU. İlmi Eserleri. Cilt 5. s.18

Memmedov,H. (1974). Seyid Azim Şirvani'nin Derslikleri. ADPU IIlmi eserleri. 1974. s. 22

Memmedov, H. (1956).Pedagoglar Seyid Azimin Müntegabı. AMEA Tarih ve Felsefe Enstitüsünün eserleri. cilt 9. 1956

Gürcüstan SSR MDT, Arh.fond-423. dosya 834. s.67-68

Azerbaycan Sovyet Ansiklopedisi. (1982). Cilt 4. Bakü

Abdullayev A. Azerbaycan Dilinin Tedrisine Dair. (1958). Bakü Aserneşir. s.107 